\title{
Potential of Traditional Culture in the Conditions of Radical Modernism
}

Asfar Askerovich Shaov

Vyacheslav Nurbievich Nekhay

Ibragim Kaplanovich Shaov

\author{
Nadezhda Aleksandrovna llyinova
}

Svetlana Aslanovna Lyausheva

Federal State Budget Institution of Higher Professional Education «Adyghe State University» (ASU) 385000, Maikop, street Pervomayskaya, 208, Russian Federation; Email: nisadgu@yandex.ru

\author{
Doi:10.5901/mjss.2015.v6n5s1p357
}

\section{Abstract}

This paper considers stages of development and evolution of the spiritual culture of the Adyghe ethnos via the specifics of interaction with the conventional culture, based on the ethnical and religious values, leading to formation of a relatively conflictfree multi-level identity, on the one hand, and between the conventional system of values and modernism values, where interactions are established differently, while disrupting totally the hierarchy of collateral subordinations, connected with the enlightening historical applications, on other hand. Acknowledgement of the possibility of various modernization trajectories opens discussion of the issue of variety of historical types or development models, while the detailed study of such types or models is not the purpose of our research. Nevertheless, the abandonment of the unilateral linear interpretation of modernization as a movement in the direction of Western institutions and values is made by us towards recognizing its multiline version, which consists in finding opportunities of own original ways of development - ethno-cultural and ethno-religious models of modernization.

Keywords: modernization, economic centralism, conventional values, religious identity, ethnical identity, secularism, globalization.

\section{Introduction}

The history appears as a number of accentuated and quite sequential events in memory of the nation, putting historical events in order, on the one hand, by means of regenerating the unique meanings, and, on the other hand, through the prism of a system of values and beliefs, and all for the purpose of learning how to function in the present and plan predictably for the future. It is obvious that we cannot remake the history, but we must comprehend the history as a valuable lesson. Comprehension of the history is comparable to man's capability to go beyond his own physical limits. However, if the history is not of determining value as a fixed experience, which was inherited from preceding generations, and the specific circumstances of the current moment are the only ones of importance, then the inheritance of the tradition loses any value, and the role of the restricted individual experience is increasing.

Are we capable and is it even legal in this context to single out spiritual records, cognitive unity not only of individual institutions, but whole periods of cultural development of a centuries-long historical road of the nation, which was taken up as the torch? After all, this intent is likely to force us to overestimate greatly the unity within the selfconsciousness of the nation against such richness of social and cultural elements with such quality of the specifics of various historical periods. One of such demarking lines lies at the population's lifestyle level and at the population's selfconsciousness level as well. We are talking about disputes that are usually spreading around the issue of hierarchical correlation of the ethnos and culture and ethnos and religion. We believe that subordination of cognition to this heuristic pattern does not allow us to comprehend and explain the leading role of any of such institutions as compared to others. Moreover, we are not able to fully single out those unique spiritual principles with them being the means for true and deep unification of the society in any difficult historical period, thus ensuring stability of such society.

This paper aims at demonstrating a relative absence of conflict in cooperation of various types of loyalty, on the one hand; we claim that the 'adjutancy' of the religion and the ethnos was not always accompanied by a conflict and 
contradictions, and thus value differences are eliminated and partially levelled out, when the religion and the ethnos are brought together and enrooted in the original ontology. The space for comparing values is broadened, and a rather conflict-free exchange takes place. On the other hand, demonstrating the way the 'interactions' are established, when the hierarchy of collateral subordinations, associated with enlightening historical applications, is disrupted. Modernizing transformations eliminate the idea of the divine predeterminacy, while increasing the degree of a chance factor, strengthening the role of a creative interpretation of the reality, which does not only broaden, but delete the boarders between socially acceptable life practices and destructive and deviant forms of man's social life.

\section{Methodological Basis of the Research}

Methodological parameters of this research include a multi-paradigmatic approach, which implies the use of social and humanitarian disciplines, such as historical, sociological, ethnological, economic, etc. In particular, in order to comprehend the phenomenon of conventional culture in the context of transformation from ethnicity towards modernism, a comparative and historical, evolutional, and ethnocultural approach is used. A primordialist approach is applied for considering the ethnicity as an expression of locality. The concept of modernism as a sociocultural and economic paradigm of social dynamics is disclosed by means of economic centrism domination.

\section{Findings and Discussion}

The genesis of 'modernity' is associated with the Renascence, and we associate the origin of a social subject of modernization, a personality that shares the modernizing ideas and fulfils such ideas in his/her real social practice with the Enlightenment (Schumpter, 1995). This social and anthropological type of personality is known as a 'homo economicus' in the scientific literature. The 'homo economicus' is a strong individualist, who has been transforming the world actively and striving for the material success and capital accrual. In this context, the modernization process may be considered as a process of establishing institutions and relations, values and rules, which requires an anticipating replacement of the traditional human identity to an identity of a society that is being modernized. The similar objective is pursued directly and obviously in modernization theories, which is the requirement for identification within the new borders that would coincide or would not at least contradict the western values and social attitudes, including rules, scores, and actions, typical for all.

Thus and so, the process of 'overlapping' is going on in case of interaction between systems involving similar basic values, which leads to a conflict-free 'adjacency'. The religious component as a value-conscious and universal one just sets the dimensions for ethnic values, while reviving the original ontology in the ethnicity, and giving it orientation on a certain reality. As a result, there are conditions, when sublevels of identical values of a social identity level out, within such social identity, the identity in the course of their interaction, while the interaction of carriers of different systems of values gives birth to a space of comparison of such systems, which may lead to a conflict. The religious and ethnic components transform the identity into a structured system of values in the conditions of total indistinguishability.

An acute social and political crisis may be an additional and powerful drive for coordination of the identity levels. This is known to lead to a stagnation and identity replacement, but not to a substitution of one or another loyalty as the final choice by the population of beliefs, including a certain set of priorities and values, which are the basis for a recovery of the ethnic and cultural integrity. A social development crisis demands a universal formula of an answer to the question about the reason for existence and social activity.

We have chosen an axiological principle, which gives, according to our beliefs, a new and very important dimension for the historical past, and answers a question about the sense of perfect equilibrium of the ethnic and religious components, their deep indistinguishability, as our methodological means. Nevertheless, the thing that destroyed such ideal of free and harmonic co-creation with time is the most important for us.

\subsection{Peculiarities of ethnic self-identification transformation in European historic retrospective}

Ethnic self-identification is of subjective psychological nature as a mechanism for ethnicity self-determination; at the same time it is predetermined and supported by the factors that are available for each individual objectively. It included regional landscape, language, religion, social organization, aesthetic and ethnic regulations etc. The ethnicity poses as an expression of locality, while limiting the overall human nature, and it leads to the grounds of the universality of culture, authenticity and essence of human existence in the conditions of forced changes, social risks and acute need of security. The population, which has been deprived of living space, loses its ideological integrity, and the old system of values gets 
loose. A search and mobilization of identifying resources takes place in the conditions of total fatality.

Religious beliefs are not, as opposite to ethnic ones, limited by the earth reality borders. The meaning of transcendental dimension comes out first in the religion. The religion allows you "to understand and interpret the life dimension, which is to some extents far bigger than we see" (Forward, 2003). Moreover, the universality of culture is preconditioned by the universal human nature, and the first historical form, where the individual actualizes his/her true substance, experience and knowledge, is expressed in the religious beliefs. However, the casuistry of the Enlightenment distorted religious narratives, replacing the deep transcendent sense of the human nature universality by a desacralized and quite down-to-earth and ephemeral consumer's nature.

Outlines of the façade a certain epoch are decorated by original facts of the historic consciousness as translated by texts, stories, literature works, fine arts, and architectural styles. However, in order to find out what is concealed behind the history façade, we need to look deeper into the beliefs defining the spirit of the epoch. The history and the population are reflected in each other and infiltrated each other at the same time (Stearns, 2010). The history 'rhymes' with the defined life circumstances, while determining, via adaptive and integrative functions, a particular society into the integral whole in order to control such society, while forming ways and objectives of the social development and giving justification of the government authority and ideologically self-defining the man.

Different levels of identity are coded in depths of the ethnic consciousness, and they give order to different levels of the reality, while been structured ontologically. Historical events are perceived with the help of consciousness; various levels of the historic existence are predefined according to various levels of identity. A certain level of identity is capable of disclosing just a corresponding level of the historic reality, e.g. ethnic level of identity discloses ethnic dimension of a historic event, and however, it cannot disclose its ontological status, which is accessible to the religious level of identity. We define a certain autonomic reality as an event and see this reality as a special and time-depended realness, in this case - the ethnic history and/or sacral one, while giving it the absolute religious tone. Here, identity is connected, first of all, to meaning-making processes, search of internal relations, and deep perception of ourselves via our own culture. There is no population in the world that would not have its own established system of beliefs. Certain moral principles are at the heart of such systems. These principles regulate social relations with the help of conventional social standard culture.

Religious identity is represented by a corresponding religious consciousness. Each population has its fundamental principles of good and bad in its archetype. Being available in each culture from the beginning, their origin is deeply enrooted in the religion, and they were filled with ethnic meanings and senses afterwards so far.

The ethnic and cultural religion materializes the history of an ethnos, as opposed to the ethnic and religious reality, being focused on the eternal and sacral idea of the absolute existence of God. Although, the actual division of these two realities is easier to do in contemplation than in practice. These two realities are adjoined and united in the original axiology. Time-dependent values broaden the borders of ethnic values, until they are connected to the absolute sense. Such circumstance presses for studying ethnical and ideological grounds for the ethnic self-consciousness, and interconnection between the ethnic and religious beliefs.

And, if such levels of the identities have formed historically in the nation's self-consciousness as the unique system of values that is common for its carriers of the traditional culture, the modernizing project of the Enlightenment was far more difficult and destroying for the entire system of the traditional culture. While being imported from outside, this project re-structured traditional society, depriving them of the integrating overall ethnic identity. A solution to the identity problem is connected naturally, to some extent, to certain types of human socialization and their specifics, depending on religious, ethnic, sociocultural and subcultural traditions. Thus, having distorted natural connections, from this moment on the discourse of casuistry of the Enlightenment started to replace the clerical power, while striving for total autocracy, which was the end for the active existence of the ethnic and religious component of the cultural tradition. It led to replacement of the genuine by the false inside the ethnic unity. The triumph of the pseudo-ethnic and cultural discourse, missing traditional genuine definitions, is now correlated with the secular and rational paradigm of the Enlightenment, which introduces, this way, an element of diversity of subjectivity with the inequality and hierarchy and non-defined set of identities inherent to it, to the society. This set of the stratified identity gives social subjects the ability to create and range multiple parallel anti- and pseudo-traditional senses and meanings. Modernization legitimizes simultaneously fundamental principles of any regular social organization, while formulating directly these principles and serving a source of resources for their regular transfer (Tassinari, 2009).

While integrating, forming intellectually and strengthening ideally various groups of the society, modernism structures the society via the tremendous effect of enlightening ideas through the oral and written language and mass media, while forming an individual, as well as existence of whole human generations. While the religious tradition exhibits itself as a system of social activity determination through the spiritual production of the language of Revelation, the 
language of Renaissance introduces into the linguistic space in struggle for cultural challenges over the religious tradition a corpus of texts, based on secular examples.

An average man is socially sensitive, which is reflected in the linguistic control of his language system. Until the linguistic procedurality finds its deflection in the teologization of the conceptual framework, while becoming public domain, the use of characters of the nature or myths is inevitable, and until the language does not develop special and clear definitions for describing social and historical processes. Workings, ceremonials, magic rituals, unwritten pagan rules deify natural forces, and self-evident laws of the natural order are material forces of social development, and all of this degenerates obviously into archaic, syncretic and vulgarized forms. Thus and so, the unique social existence in the social space is gradually losing its steady status and shapes up as anonymity and 'uncontrolled item'. The world order, which is defined by the mystic consciousness, may no longer be considered self-sufficient and significant, as long as it became inexplicable due to losing the image of the universal and eternal man. While identifying the modernity as a variable everyday life, 'homo ethnicus' compares it with the original concept of world variability, and the man is appears motionless, spiritually static and eternally identical to him. The unity of ritual immanency and ideal transcendence leads him to the capability of improvement and allows for development in other forms of existence. The language of the ethnic tradition is the language of nature; it defines actual and real tangible boundaries on the way of constant movement of alternating images. Within the boundaries of such language, each thing finds absolute microcosmic confirmation, which affirms the visible order of heavenly bodies, seeable mountains, rivers, with their restricted scale amplified by a simple addition, while not adding any vague metaphysics of structural stability. The language of eternity gives multidimensionality to the language of tradition, broadens the language of tradition from the microcosm to the macrocosm due to incorporation of symbols and signs of Revelation.

The nature, being a system of signs and similarities, opens on itself via the language of eternity, which is oriented neither on the oral words, nor on visual representation, and which does not subordinate to them, but, to the contrary, with view to the change of language status, the language now subordinates the Nature itself.

In the past, the spontaneity of the language correlated with the elements of Nature; now, the homogeneity of the language space correlates with the homogeneity of the ideological space in its overall relation to the world's omneity, while expressing the truth, oriented towards the eternity. The register of the written speech re-formatted the oral speech, while enriching the language communicatively altogether. The oral language tradition and religious written tradition formed the uniform linguistic standard, which allowed forcing the mechanism of mobilization of spiritual resources and translation of such sources via various social networks. The unity of the community escaped cultural subdivision due to uniting around understanding of the text of Revelation, which expressed live religious feeling. The ethnos accepted the challenge of the history via the prism of language parallelism as a standard, i.e. linguistic behavior, and language as meaning space, i.e. social behavior. The result was a language as a reflection of the spiritual consciousness, i.e. the absence of any tension between the transcendent order and social order.

\subsection{Ethnic and cultural transformation in the conditions of search for paradigm of cultural and historical identity}

Long-term transformations of spiritual, social, and, thus, personal structures of the Adyghe society have already been conceptualized sufficiently in the language system and they adapt easily to the historic representation of the outer world. "The fundamental codes of a culture - those governing its language, its schemas of perception, its exchanges, its techniques, its values, the hierarchy of its practices - establish for every man, from the very first, the empirical orders with which he will be dealing and within which he will be at home". (Foucault, 1994)

A notable parallelism of the limited ethnic (material) and religious (abstract supramaterial) arises as the first stage and it ends in the stage of their organic twinning.

It seems that total transformation of all ways to self-cognition and moral awareness happened on the second stage of the genetic restoration, a new and integral and powerful system of thoughts and feelings was born and the whole mass of former spiritual values was processed in this system of thoughts and feelings, a system that comprised sprouts of all ethnical, materialistic and religious and idealistic concepts of the new times, a system, where former beliefs were not only pushed behind but potentially overcome as the present for good.

Here, with no economic interdependence or integration of large territories available (or just being established), other form of integration is more powerful than the economic one, i.e. military integration, solidarity in mutual protection against the common enemy. Besides the traditional feeling of solidarity, it is refreshed by the solidarity of the religious belief and finds the clergy as its most important patrons, but it never prevents any disruptions itself, and it only amplifies and directs one alliance or another, i.e. strives for collective security turn out to be the most important knots keeping together people that are spread across different people shares. That is why the solidarity of such society is so unstable 
(as compared to later times) and axifugal trends are so strong in such society.

These two phases of the society, where the natural economy prevails, i.e. the stages of conquering and protection, alternate each other often, as was mentioned before. Shifts happen in one direction or another and the history of establishment of the Adyghe nationhood may serve as an example. A strive for social integration that is based on the awareness of full indistinguishability between the ethnic and religious orientations affected the social equilibrium; moreover, the new definition pointed out the necessity of evaluation of the social order in categories of the transcendent model, which was indicative of the elite in power becoming responsible against the claims of the traditional order.

If we analyze the correlation of levels of the ethnic and religious identity in terms of belief functions that are fulfilled in the society, they will be identical in many aspects. The interaction of the systems of values of the ethnic and religious beliefs leads to a modification of the system of world perception and world outlook of the population.

Thus, the process of 'overlapping' is going on in case of interaction between systems involving similar basic values, which leads to a conflict-free 'adjacency'. The religious concept as a value-conscious and universal one just sets the dimensions for ethnic values, while reviving the original ontology in the ethnicity, and giving it orientation on a certain reality.

First contacts are made by means of exchanging new similarities, and then the general order of collateral subordinations is established via coupling, merging, and coordinating and it is similar to the figurative correlation between the soul and the body. While being related from the beginning, these two phenomena are subordinated collaterally to each other, and thus are free from any chaos, randomness and shift of the border, the continuity of which establishes the unique and straight system of world outlooks. The discontinuity of the border between the ethnic and the religious will further lead to ethnic-cultural and ethnic-religious phenomena to be placed, located, and laid out here in planes that are so different that no one could find any meeting space for them and define the common place for both of them.

The conditions where sublevels including identical values will level out the social identity, when interacting with each other within such identity, will be established as a result. Then, the interaction between the carriers of different systems of values will generate a space for their comparison, which may lead to a conflict.

The ultimate existence of the ethnic and cultural as a whole starts to justify itself here, and strive for a rational restructuring of all sides of the social reality, thus abolishing the metaphysics of the infinite.

There is a search of correlation of particular ideas going in the evolution of relations and presentations in time, their binding structure in each historical period, which usually leads to the syncretism, i.e. the attribute of the eclectic, superficial awareness that covers just superficial differences between one provision or another, while ignoring their deep relation at the level of common spiritual structures.

\subsection{Enlightening paradigm in the discourse of secular narratives}

The splitting of the uniform ethnic-religious and ethnic-cultural ideological space gives an opportunity in the end to make changes in setting symbols of the collective identity (Shestakov, 1981).

The conditions of self-regulation of the structural nucleus of the society, which is based on recognition, cataloguing and approving a certain hierarchy of meanings and values of the existence and code of conduct in the world, are destroyed. Within its framework the issue of destruction of the sense and purpose of existence, i.e. word outlook, changes the mechanism of movement of the historic life of the ethnos and makes it impossible to rely upon its own metahistoric social strategy, which is based on the deep indistinguishability of religious Islamic and ethnic-cultural Adyghe values.

The enlightening anti-religious ideal is spread onto the ethnic and cultural tradition, while speeding it up in the direction of self-limitation of the transcendental, making it look so insignificant and even excessive for the ethnic (everyday) consciousness, while feeding up the egocentrism with the claims to comprehend its historic experiences via the generated enlightening paradigm, which sanctions de-coding of the cultural nucleus. However, under the stress of unifying enlightening determinations, egocentric orientations started to feel increasing discomforts as a result, while declaring its own exclusiveness, and sometimes finding it hard to even confirm its ethnic identity.

"No enlightenment can occur without destroying the effect, thinking-from-a-point-of-view, and without dissolving conventional morals" (Sloterdijk, 2001).

With the help of non-religious universalities, the ethnicity is deprived of its human sense, and is no longer an object of contemplation, and it gains functions of a myth, and, therefore, serves as naivety, making the man uninvolved. The Enlightenment blocks spiritual intentions of the population, on the one hand, and strengthens in every way a unilateral interpretation of freedom, on the other hand, but not as the right to choose the comprehension of the absolute principle that is given in the Revelation, but as an intellectual construction that is brought to the level of a religion and that is 
presented in illusive down-to-earth categories.

To the contrary, religion endeavors transformation of the ethnicity back to the sense, makes its concept as abstract as possible, and tries to discover all of its potential, while hoping to get round in the end to something that could be called a transcendental attribute of the thing and its natural meaning. In this context, any culture involves a symbolic order that has been prescribed by its original codes and brings the ethnic in full compliance with the religious, to the point of equilibrium, to the point of pure reciprocity. The task of the religion is exactly to give the historically predetermined intentions the status of something transpersonal, and bring the historically passing facts to the level of the eternal, while not distorting the set perspective.

Regulation of attractions and affects was becoming further and further comprehensive, steady and stable in this process of social selection. The area of social memory 'articulated' the broadening of the mind field by means of correlating the present moment to the past and future series of events, while making the affective life of an individual irrelevant, i.e. non-consistent with its purpose, under the pressure of the institutionalized tradition, as well as applicable situation.

Demographic fluctuations towards population increase or decrease are among the most important factors, causing changes of the structure of human relations and corresponding institutions. It may not be cut off the whole dynamics of social transformations. At the same time, it would be wrong to think of it as an 'original drive' of social and historic changes of some sort, even if it appears so at first glance. Nevertheless, a forced impact of social powers is manifested extremely clearly exactly due to demographic changes. We just have to investigate the role of similar factors played in the stage of development that is of our interest. A brief overview of the latest stages of a tragic migration can help us to understand this. During this period, the proper functioning of conventional mechanisms of social control, former forms of socialization, integration, social structure and culture were ceased.

Thus, the ethnos that is brought to the edge of disappearance in such turning points of the history, like in the conditions of external military expansion, has to make its choice. The strength of the identity instinct is multiplied, when the ethnic society finds itself in the border-line conditions. The former ethnicity space is constricted and its translation channels are narrowed down. Something that was previously considered as the basic identity is of transient nature in the conditions of identity overlapping. A similar identity crisis is indicative of its critical development stage and inevitability of its total transformation. In order to prevent the total collapse, the ethnicity is in need of another development vector. Having broken the borders, the ethnicity is now oriented on the principle of higher order.

There are no strictly outlined borders between the identity levels. The identity structure is susceptible to timedependent transformation, and it is expressed in various modifications of the historic individualization of an ethnos within the framework of such ethnos. Due to external or internal 'irritants', the process of identity ranging is forced as the necessity to satisfy the arising needs, and, consequently, harmonize them in some way.

Ethnic parameters of the culture are merged with the religious ones. Thus and so, there is a combing of two different historical flows, ethnical and communal and mental and spiritual, and ultimate merging of the man-sized world with the world of man's spirit. A struggle for survival of the culture and civilization, progress ideas and traditions, spirit and material is possible here, as well as the cumulative experience, ensuring the evolutional development of the unique spiritual organism. As for our case, such changes involve target settings of the ethnic self-consciousness in terms of a crucial change of the outlook and attitude, and a new correlation to the infinite. In parameters of the ethnic culture, the absence of any representations of their predetermination and predefinition created a trend towards critical re-evaluation of the facts of man's existence. To the contrary, a symbolic area (Islam) has traditionally got historical characteristics and universalistic origins and clearly developed most important institutional areas, and development of concepts of an alternate cosmic, social, political order, all this ultimately led to strengthening of the transforming capabilities of the Adyghe society.

Replacement of cultural orientations usually targets the scope of accumulated resources for transforming the structure of institutes and capability to institutionalize the potential of changes, which exists in one society or another.

The ethnic component of the ethnic culture is focused on its own interests, while narrowing down the historical space on itself in the absence of any transcendental and pragmatic standard, which is fundamental for such discourse, and deprives it of its drive for creating the universal process that would make involvement in such discourse abiding and such discourse would reflect the religious and metaphysical totality of the historic existence. While being autonomous, local, a-metaphysical, a-theological discursive ethics, it goes beyond its own borders there and then, when it receives into itself a belief in the meaning of the transcendence ethics, responsibility ethics, in its capability of defining and justifying the theological and teleological existence metaphysics of the nature and moral and personal legal liability. We offer to refer to metaphysics here not as a system but as a subject matter, a fundamental act of consciousness centering and turning to the sacral. 
In the end, even if the interests differ greatly, the religion may define discursive moral standards of living together at minimum level of agreement, while establishing the universally binding canon. It has the right to prescribe, and thus obligate for individuals to take control of their metaphysical potencies, determine their life purpose, goal and sense, and their views of the objective meaning of general value.

Religion establishes an abstract means of public regulation, which is based on objective laws, making it possible to control relations between people without developing any subordination relations between them. Religious order must implement, via moral improvement of the man, social order; therefore, common everyday level is a point where two value dimensions, which can either reinforce the social equilibrium, or upset the balance of power of the structured life, meet (Eco, 2003). Religious beliefs did not destroy, but, to the contrary, anchored conventional ethics, and ethnic values facilitated an adequate perception of transcendental values that are beyond the social predicament. While growing into a new and structured social space, the man was still a carrier of a variety of attributes of the old culture, its regulations and values, and, at the same time, he enriched his social experience and knowledge of the world in accordance with the diversity of the world of the inexhaustible Universe. The individual now goes beyond its own fate, looks up to a higher level of meaning, purpose and metahistory, while joining in the immortality as a process leading to the infinite, and acquiring the true individuality, belonging to God, and responsibility before God.

In overall, the social conflict brought into action spiritual intentions, which mobilized to the maximum extent and forced social resources, and the metaphysical leap re-structured the space and changed the time, and that was what predetermined its cultural outlines in the future (Nekhai, 2009).

\subsection{Ethnic culture as a traditional metasocial institution}

Ethnic culture conserves the established conventional rules, traditions, ritual, ethnic values and places the ethnos in the static state in the absence of the definitive meta-goal. The ethnic culture ensured existence of the ethnos as an individual value with no relation to the genesis and ultimate goal, and its self-value was asserted just with strengthening of the religious beliefs via a projection onto the eternity. Religious ideology is based on metaphysical evidences of the existence of God and, due to the fact the religious world perception is timed, periodized and temporalized systematically and defined geographically in its origins, it is a targeted process. As an example of the religious identity in our research we proceed from the fact that Islam has come to stay not so in the Adyghe everyday life, bypassing its consciousness, i.e. an outlook that is reflected in works by most researchers of the Adyghe culture, but rather to the contrary, as far as we believe, Islam has become quite perpetuated in the people's consciousness in order to come into their everyday life.

The ethnic landscape that was once full of episodes of historical events of the planar realism was replaced abruptly by an abstract representation of the history that is oriented metaphysically and where the full composition of the canvas was exhibited, including the three-dimensional perspective of inclusion in the overall process of world history establishment, while reflecting the other world and using a palette of more and more rich and fine colors against the cosmic and historical background. Religious beliefs integrate any differences between the past and the present, while taking a step towards the eternity and thus connecting the historical existence with the eternal existence.

Overall, it should be mentioned that the identity formation through a conflict is still a matter of discussion within the traditional institutions (Brewer, 2006). To the contrary, the Enlightening paradigm generated a collision of rational innovations and traditional ethnic grounds. While disrupting the continuity with regard to common principles of the cultural identity and announcing the tradition unreasonable and totally archaic, as long as it is based on false assumptions, which are not engraved in the mind. The mind substitutes for the unconditional Absolute and it is considered as an autonomous and universal category, while stagnating or filtrating, in best case scenario, the tradition from preconceptions. The mind verifies compliance of the traditions with its own parameters that have been established voluntarily and where the universal enlightening anthropologic model of a 'man as a measure of all things' imposes conceptual senses that are not based on any original spiritual 'supposition', the 'big idea', an original symbol or ultimate sacral value, which would assign a specific meaning, consistency and unity to all other elements and components, on the 'man of tradition.' The modernism, which took control over the ideological space and fulfilled an independent 'enlightening' tradition in such space, has been gradually shaped and articulated via social actions and political practices in the social and cultural existence of the ethnos.

The ethnic-cultural and ethnic-religious traditions differ from the modernism discourse in the line of understanding the normalization of the history. On the one hand, economic and technological determinism of modernizing objectives and programs reshapes social layers of the reality and life and practice approaches of people, and, on the other hand, a secular and rational approach asserts 'achievement-oriented' orientations of human's activity. Ethnic-cultural and ethnicreligious dimension of the uniform ideological space implied the ethnic consensus, which formed the unity of the spiritual 
dimension of the existence. It required a rather long-term historic retrospective of the events, in order to fix and explain quality interactions of the ethnic and religious values. Lifting monopolistic and traditionalistic ways of regulation allowed for aligning the ideological space configuration with various ethics.

There is a regular need of reproducing modernism as a radical transformation process for the present that is predefined by its inner logic, i.e. ignoring the past, exploiting the present and fruitless anticipations of indeterminate future, which allowed for releasing from responsibility for any consequences of the social transformations.

The enlightening project in West-European culture was openly anti-Christian already at its dawn, and, while taking up the leading positions, made claims regarding the humanistic universalism being its foundation. As a result of forces of 'earth gravity' it was reduced to the state of ultra-individualism, which deformed all conventional forms of social production, destroyed the religion, and all social grades and connections, all organic relations of closeness, which were, first of all, relations of solidarity and mutual aid, along. For historical reasons, thinkers of the Enlightenment ages gradually forced out the unquestionable Divine law of the European culture in their struggle against the religious tradition, and replaced it with an imperfect human mind, subjective rational moral and doubtful and unpredictable concept of social progress, expressed in classic political ideologies. At the moment, these are various modifications of conservatism, liberalism, Marxism and nationalism.

We evidenced their system crisis or total fiasco in the $20^{\text {th }}$ century, and the project of Enlightenment, including its unreachable ideal, is called more often no other than the 'era of Blindness' in the scientific literature. The principal idea, which unites the founders of the project of Enlightenment, is a thought of indefinite, intellectual and social improvement of the man, with mind being its primary criterion and drive.

"Belief in the progress of humanity, moving towards more and more high and perfect state, to the Eden on earth, to the "light' etc. is one of the most harmful misconceptions that were inherited from the 19th century" (Bochenski, 1993).

Cognitive, organizational and institutional structures of natural and social sciences and education were established and still subsist untouched with freeing the man and creating the unique civilization that would eliminate any moral rituals based on traditions and religious beliefs, as their targets against all of their differences. However, decay of former moral forms under the effect of imaginary freedom just started the progress of illusions, which turned out to be a spiritual slavery for the man in the end. "The domination of the market, production and bureaucracy over individuals has been increasing for the last two hundred years. Consequently, there is no sense to talk about any progress. To the contrary, degeneration of the European society and culture took place" (Makarenko, 2000).

\subsection{A modernizing potential of the economocentric society: habitus of the Enlightenment}

Modernization is obviously a complex process that covers all areas of the social life, such as economic, legal, ethic, aesthetic, political, cultural; however, we associate any changes in these areas primarily with the effect of market structures on such areas. Modernization means, in terms of economy, transition to the capitalism of Western type, ensuring functions of the capital and creating a social and cultural and political environment, adequate to the capital. As long as functions of the capital may be fulfilled even before the capital and beyond the capital, Western modernization consisted in making the society, policy and culture adequate to the capitalist entrepreneurship (Eisenstadt, 1999).

Such consecutive economic dimension of the society also leads to significant consequences. Completing the process of secularization and 'excarnation' of the world, which was characteristic of the modernism, it ends in 'dissolution' of the social, e.g. disappearance of nations, losing their specific distinguishable attributes. The outlines of the social system are now nothing more than the simulation that disguises the absence of the 'multi-sense reality', which clearly means the value-conscious worldview of the Modernism era.

In terms of social science, assertion of the economic order leads to social stratification into producers, owners, and alienated strata. In terms of collective concepts, such process leads to assertion in the most honored place of market values that were considered the lowest in all times before that. This is not random, as long as they are caused by a low vital necessity. In terms of moral, it rehabilitates the spirit of interested settlement and egoistic behavior that was judged in all traditional societies.

Classic enlightening ideas are not so clear, to be honest, as compared to their analogies in Europe; if we extrapolate such ideas and apply to Russia, there are specific syncretic ideal and philosophic concepts. The Russian Enlightenment of 1840-1860 of the $19^{\text {th }}$ century reflected not only internal contradictions of the Russian society, but also contradictions between the self-consciousness of the Russian society and practice of the social life of more developed Western European countries, where rather mature forms of enlightening type were presented already in the said 
decades. One way or another, adoption of western templates is always inevitable for modernization. West usually initiated modernization (or westernization as its radical form), and colonization was the principal model of its fulfilment, with the attempt to bring lagging continents, countries and regions close to the developed ones used as their excuse (Titarenko, 2006).

We believe such peculiarities of the European Enlightenment to be also typical of the Russian Enlightenment of 1840-1860, which also predefine specifics of it being carried over into the soil of different, in terms of developmental stages, cultures and civilizations. A model of catching modernization is the most catastrophic scenario for the traditional cultures. For our case, the peripheral regions of the Imperial Russia had to face the 'effect of duplication', while doomed to always catch the infinitely receding Western project, as well as a lagging Russian analogue.

This new spiritual trend in the Western culture, which further swept the whole humanity, led to new forms of public order, social stress, and, in the end, to catastrophes in the business and social life, such as global trade and capitalism, based on the usurious lending; nationalism and imperialism; in arts to reneging on normative ethics; in law to independence from the order that had been established by the religious laws; and in spiritual production to dominance of natural sciences and unbelievable technical inventions that were further on considered a more and more important index of the degree of human progress.

It is obvious that we do not dispute, but rather fully support the term 'enlightenment' as a process of natural and mutual effect and spread of cultural, scientific, technical and other achievements of certain civilizations and achievements of the global culture in general.

However, the expanding global alienation of social support and public solidarity that is going on today (Schiller, 1991) yet again was the result of the intellectual decent of the project of Enlightenment and its ideological attack on all areas of the social life, the 'central matrix' of the traditional culture was deformed, the ethnos lost the integral system of value coordinates, which was held together by the common religious doctrine. New values, targets come into the everyday life gradually; new life practices and models of conduct are affirmed.

While structuring mythologically the historical space, the paradigm of Enlightenment is unfolded via a set of subordinated historical applications, which have been defined from the winner's point of view. It does not only create an inadequate image of the ethnic history, while distorting the traditional world outlook, but also brings mythological enlightening traits into it, while determining for a certain needs of the cultural and civilization environment. Initiation of the enlightenment, provided its outcome is successful, must facilitate elimination of the archaic and taboo, and syncretic traditional consciousness, making it possible to speed up greatly the development of individual life strategies, which are intended for public recognition and some profit gain. People are gradually becoming an object of rational monological investigation, human objectivation ceases its existence, 'dehumanized humanism' is destroyed, the model of the 'man' is abandoned, and the man is transformed into a monological superficial object.

All dimensions of the 'I' and 'We' were reduced to a simple 'this', atomistic or integral, depending on your beliefs, it only possessed the criterion of functional suitability. Application of a similar functionality to the subject was found in the economic area, which was the one to announce sovereignty in the absence of monopoly for the meaning and purpose of the existence.

Heaps of people, who did not have any suprapersonal consciousness or collective will, were freed up with the loss of the religious identity at first and blurring of ethnicity lines as a result (Jackson and Molokotos-Liederman, 2015).

Today, sociality is transformed into a silent majority, which is not any institution to be referred to as to a class or population once before.

These processes may be explained by any manifestation of an individual creativity in traditional cultures, where it cannot become a creative message, unless it agrees with the standards of the collective consciousness, which make any manifestation of artful creation 'legit.' In context of this real situation, a revival of the 'cultural myth', which was known as the Enlightenment in the history of humanitarian sciences, goes on. This cultural project forms a high status of the creator; this historical situation predetermined the enlightening nature of relations between the leading figure of the creator and the led figure of the consumer. The enlightening model is conditioned by some or another social paradigm, which corrected relations between these figures, depending on the social world outlook. Postulates of the Enlightenment determined the straight thinking system, while acting in the consciousness rather consistently, and acting as the voice of reasonable mind or appealing to the reasonable mind. The rationalistic image of the culture is derived from the common origins and settings of the enlightening 'ideology.' Active aestheticization of social phenomena and transformation into the aesthetic reality of various manifestations of the social reality changed drastically the eternal object of the aesthetics, i.e. the beauty, from the transcendently oriented mind to the immanently social as a result. The enlightening philosophic anthropology is based on the unlimited need for achieving more and more freedom by the man, improving forms and means of his activity, and is, in the end, expressed in expanding the area of rational, its attack on the area of irrational. 
Having assimilated the irrational, the changes now aim at broadening human's rational consciousness to the social borders and place the human in the 'comfort zone' within these certain social and historic conditions.

Deconstruction of moral values of things is 'sublimated' in the Enlightenment times into a group sanction, while becoming the only one possible criterion of valuation, and while structuring hierarchically the perception in a way to require extraordinarity and out-of-the-box artistic thinking for reading a creative message, which claims to be a masterpiece. This is reasoned that aesthetic feelings are achieved by falling deep into hazy and unsteady, complex sense bearing and in the end ambiguous associations, which requires a cultural and historical context for their comprehension. Therefore, any other interpretations are ignored, e.g. as encouraging sexual activity or reading literally artful ritualization of obscenities. It is subjected to radical irony as a result and it is interpreted as a questionable and undeveloped aesthetic taste.

There forms an impassable gap between cultures from different levels, which provokes unsuccessful attempts in achieving the established cultural standard, on the one hand, and cultivates a feeling of inferiority of one's own ethniccultural and ethnic-religious tradition, on the other hand.

As long as the process of forming the ethnic self-identification is a historically primary function of the ethnicalcultural tradition, this process served as the cementing ideological fundamental principle of the self-consciousness of the Adyghe ethnos at early stages of ethnogenesis in the ethnic self-consciousness of Adyghe people. Social and historical changes are getting further deeper and deeper. The very system of guidance to follow is being developed, complicated and changed. The replacement of symbolic areas entailed large-scale changes, including those of political institutions, channels and principles of access to the power are being changed. With conversion to Islam, the Adyghe society saw the changes associated with reforming of the governing elites and with shifts in the social and political organization, and in the ability of self-expression of wider strata of population, and in the impact of these strata on the political processes and changes. Principles of hierarchy and power distribution in the society were drastically changed. Religious and ideological changes implied re-structuring of the symbols of political power and their legitimization.

Political, economic, social and symbolic structures of the Adyghe society are changing at large. In all these changes the most significant for the history of the people is the fact that the minor events recede to the background, but senses remain.

In particular, doctrinal nature of the Islam called for a high level of reflection oriented on comprehension the principles of spirituality, religious provisions and prescriptions. Overall, appearance of political, social and cultural structures that were based on the religious principles facilitated transition to the modernity and made it easier.

\section{Conclusions}

Thus, it should be pointed out first of all and in conclusion that the project of Enlightenment is responsible for origination of the modernization process as a macroprocess of transition from the traditional society to the modern one. Modernization is primarily a social and cultural process of active development of a new system of values. The pulse set by this movement was also transferred to other regions of the world, while transforming radically their ethnic-cultural and ethnic-religious world and forcing obviously into application (colonization) or manipulating casuistically mechanisms of functioning of traditional societies, predisposing them to the forced borrowing from the 'enlightening nations' not only technical innovations, economic models, political regimes and social mechanisms, but also customs, values, codes of conduct, cultural templates etc.

Implanting of templates from different cultures marks a transition from the prevailing adoption of communal and communitarian values to individualistic values and to legitimization of the life success strategy. Borrowing and adoption of ready-made cultural templates is a constant effect of the catching modernization. Variability of the systems of values from ultra to neo-cultural states of modern societies includes the possibility of positive and negative development scenarios. A co-existence conflict of traditional values and structures, involving modernized forms and elements of the modern societies, likely takes a negative meaning. A traditionalistic axiological complex is gradually penetrated and smeared out by the new utilitarian morality. We are not even talking about the absence of dichotomy of the good and bad as eternal categories, which inevitably leads the modernity to 'pathology', and a situation of pluralism of ideas and systems of values, which generates a sheer cynicism.

Ideas of modernization as an objective and natural historic process of universal and global or specific and local nature are essential. Thus, if modernization is a specific local project of the Western European culture, how is it that it can appear as a certain stage of development, a quite natural process of transition from agrarian, pre-industrial traditional societies to industrial ones, and then post-industrial societies (Servan-Schreiber, 1968). This process is instrumental and artificial, and, therefore, it is designed and controlled by someone, in which case it is a forced modernization by countries 
of the North-Atlantic civilization of modernity, which shows, first of all, its radical destructive side, i.e. distortion, disruption and degrading of traditional structures.

Before the modernity was inoculated by the paradigm of Enlightenment, the tradition was equivalent to itself, and now it is identified with modernity (Latour, 1991). Since the modernism has focused on the present, the 'ghost of modernity' has been lingering over the traditional culture, where the modernity is the same as the current moment, eventually reduced to the logic 'nothing' by the post-modernism. Various attempts were made to adapt the developing societies, which included their 'heavy load' of inherited traditional values, to the modernization process. The outcomes of such transformations led, in best case scenario, to 'social hybrids' and to a perspective of becoming a 'social mutant' in worst case scenario. All past experience of social regulation, a complex of achievements and values of a certain society was just considered from the point of incorporation into the civilization of modernity, which was created by the West.

It is obvious for us that in the absence of the potential of tradition the modernized structures simultaneously 'utilize' and substitute traditional parameters of the culture.

Therefore, the modernity looks like problematization of detraditionalization, when viewed through the prism of cultural praxeology. Detraditionalization may come out as a creative process in a traditional society, in which case elements of the modernizing social system are introduced correctly under the effect of religion or any other factors that are supported by the religion, while the foundations of the traditional society are left untouched and are anchored to the altered conditions (Shaov, 2010). Therefore, we are in need of an alternative modernization process supported by the potential of ethnic-cultural and ethnic-religious tradition that fits well in the context of the national history and that is based on sovereignization of the man of tradition, who relies on the combination of identical religious standards and ethnical traditions, regulations and ideals of the science, while acknowledging and orienting on the parameters that are beyond the manifested world. Acknowledgement of the constructive and positive role of the social and cultural tradition in the process of modernizing transition was pointed out in particular by Edward A. Tiryakian (Tiryakian, 2009), who suggests to review the matter of the religion role in the modernization process in view of new historical realias. The role of religion may be quite significant, as long as it motivates, legitimizes and mobilizes the masses for social actions and changes.

Clearly, the ideas that are presented in this paper require a more systematic expression, which we will presumably attempt in the future. We do not claim to present the final solution within this paper, and we have just pointed out several directions and aspects that correspond to the tasks of this research.

\section{Acknowledgement}

This paper has been prepared within the project No 15-18-00148 of the Russian Scientific Fund

\section{References}

Bochenski, J.M. (1993). Sto sueverii (Sto zabobonow: Krotki filozoficzny slownik zabobonow) Translated from Polish - Moscow: Publishing Group 'Progress' (187 p.). [in Russian]

Brewer, B. (2006). The Discourse of Enlightenment in Eighteenth-Century France (316 p.). - New York: Cambridge University Press

Eco, U. \& Eisenstadt, S.N. (1999). Revolutsia i preobrazovanie obshchestv. Sravnitelnoe izuchenie tsivilizatsii (Revolution and the Transformation of Societies. Comparative Study in Civilizations) (415 p.). - Moscow: Aspect Press [in Russian]

Eco, U. (2003). Iskusstvo i krasota v srednevekovoi estetike (Art and beauty in the Middle Ages) (256 p.). - Saint-Petersburg: Aleteia [in Russian]

Shestakov, V.P.(Ed) (1981) Estetika Renesansa: antologia / pod red. V.P. Shestakova [Aesthetics of the Renaissance: anthology] (495 p.). - Moscow: Isskustvo [in Russian]

Forward, M. (2003). Religia (Religion) (320 p.). - Moscow: Grand-Fair [in Russian]

Foucault, M. (1994). Slova i veshchi [The order of things]. Retrieved from http://webreading.ru/sci_/sci_philosophy/mishel-fuko-slova-iveschi.html. [in Russian]

Jackson J., Molokotos-Liederman L. (2015). Nationalism, Ethnicity and Boundaries: Conceptualizing And Understanding Identity Through Boundary (252 p.). - New York: Routledge

Latour, B. (1991). We have never been modern (348 p.). Harvard University Press

Makarenko, V.P. (2000). Glavnye ideologii sovremennosti [Basic ideologies of modern times] (480 p.). - Rostov-on-Don: Phoenix [in Russian]

Nekhai, V.N. (2009). Sovremennaia globalizatsia kak mnogourovnevyi i mnogofaktornyi protsess [Modern globalization as a multi-level and multi-factor process]. Vestnik Adygeiskogo gosudarsrvennogo universiteta, vyp. 1 (Bulletin of the Adyghe State University, issue No 1) (pp. 120-125). - Maykop: Publishing House of the Adyghe State University [in Russian]

Schiller, B.R. (1991). The microeconomy today (594 p.). - New York: McGraw-Hill, Inc.

Servan-Schreiber, J. (1968). The American Challenge (201 p.). - London: Hamish Hamilton 
Shaov, A.A. (2010). Rekonstruktsia protsessa stanovlenia i razvitia etnokulturnogo i etnoreligioznogo mirovozzrenia adygeiskogo etnosa [Reconstruction the process of formation and development of ethnic cultural and ethnic religious beliefs the Adyghe ethnos]. Bulletin of the Adyghe State University. Regional studies series. Issue 1, (pp. 18-28). Maykop: Publishing House of the Adyghe State University. [in Russian]

Schumpter, J. (1995). Capitalism, Socialism and Democracy. (540 p.). - Moscow: Ekonomika [in Russian]

Sloterdijk, P. (2001). Critique of Cynical Reason. Retrieved from http://www.chitaem-vmeste.ru/pages/review.php?book=415\&view=abcauthor\&pn=51 [in Russian]

Stearns, P.N. (2010). Globalization in the World History (168 p.). - New York: Routledge

Tassinari, G. (2009). La globalizzazione (124 p.). - Milano: Alpha Test S.r.l.

Tiryakian, E. (2009). For Durkheim: Essays in Historical and Cultural Sociology / Steven Lukes(Ed.). (362 p.). New York: NY University

Titarenko, S.A. (2006). Spetsifika religioznoi filosofii Nikolaia Berdiaeva [Specifics of the religious philosophy of Nikolai Berdaiev) (288 p.). - Rostov-on-Don: RGU [in Russian] 